【Review】

\title{
Application of Atmospheric Pressure Plasma Oxidation and Plasma- Induced Polymer Coating to Surface Functionalization of Textiles
}

\author{
Keiko Gotoh\# \\ National Institute of Technology, Nara College, 22 Yata-cho, Yamatokoriyama, Nara 639-1080, Japan
}

\begin{abstract}
Surface functionalization of fibers is one of powerful meanings for improvement of textile performances. In this review, two atmospheric pressure plasma jets (APPJ), plasma oxidation with nitrogen gas and plasma-induced polymer coating with hexamethyldisiloxane, are utilized for the surface functionalization of synthetic fibers, poly (ethylene terephthalate), PET. The PET film with a geometrical simplicity and natural fiber, wool, are also used as materials. The topographical and chemical changes due to the plasma-PET surface interaction are clearly observed after the APPJ treatments. The APPJ oxidation roughens the PET surface as well as increases the surface atomic oxygen concentration, which makes it hydrophilic. However, remarkable hydrophobization is achieved after the APPJ coating as a result of the deposition of inorganic $\mathrm{SiO}_{2}$ films and the granular morphology formation on the PET surface. The APPJ oxidation after the APPJ coating makes the PET surface super-hydrophilic. Surprisingly, the APPJ-coated PET surfaces with and without the APPJ oxidation have no contact angle hysteresis and preserve the contact angle to remain almost constant for at least two weeks. With respect to textile performance, the antifouling property of the PET fabric is found to be controlled by the APPJ treatments: soil deposition in air is prevented after the APPJ coating and soil release by laundering is promoted by the APPJ oxidation to the pristine and the APPJ-coated PET fabrics. Water wicking into the PET and wool fabrics is remarkably promoted by the APPJ oxidation. The dyeability of the PET fabric by dispersive dyes is improved by the APPJ oxidation before dyeing. For the wool fabric, color deepening after ink-jet dyeing is significantly increased due to pretreatment by the APPJ oxidation compared with the chemical treatment.
\end{abstract}

(Received 6 May, 2020; Accepted 21 June, 2020)

\section{Introduction}

Textiles, which are commonly composed of fibrous assemblies, are used not only for garments, carpets, curtains and furniture but also for industrial use. To obtain high performance depending on individual applications, surface functionalization of fiber has been carried out primarily by wet chemical processing [1-6]. This technique modifies the surface chemical structure due to a chemical reaction, such as esterification, grafting, or crosslinking, and therefore large quantities of agents and solvents are required, resulting in undesirable, expensive drying and pollutant-treatment steps [6, 7]. Moreover, the usage of chemicals often damages the inherent properties of the fibers such as its mechanical properties [6].

Growing demands on the high functionalization, as well as on the eco-friendly finishing processes, have spurred interests in replacing wet chemical treatments with dry physical treatments in the textile processing. Among the physical techniques, dry gasphase oxidation by plasma technologies has been most often attempted for fiber surfaces [8-17]. However, plasma treatments are commonly performed in an evacuated chamber, which often requires significant amounts of time, energy, and space [18].

Recently, atmospheric pressure plasma jet (APPJ) apparatuses have commanded considerable attention because they generate plasma plumes in open space, do not limit the size of the objects to be treated, and can achieve rapid, continuous in-line material processing [19-25]. Many researchers have attempted surface oxidation of synthetic and natural

\# corresponding author: Keiko Gotoh (E-mail: k-gotoh@jimu.nara-k.ac.jp) 
textiles using an APPJ device [26-29]. We have applied the APPJ oxidation to the finishing treatment of synthetic polymer film and fiber using a commercial APPJ device [30-34].

Lately, atmospheric pressure plasma-enhanced coatings based on chemical vapor deposition (CVD) have also been developed for industrial applications. We have also attempted hydrophobic treatment of PET and cellulose films by APPJ coating using siliconbased precursors, and successfully obtained extremely water repellent surfaces [35]. Moreover, it was confirmed that the APPJ-coated surface became super-hydrophilic when it was oxidized by APPJ [36, 37].

Here, we review the experimental results with respect to the surface functionalization of textiles, mainly PET, by the two APPJ treatments, namely APPJ oxidation and APPJ coating. PET resins account for approximately $80 \%$ of synthetic fibers of the global market, and they have high mechanical strengths, good stretchability, wrinkle-resistance, heat setting, rapid drying, resistance to usual organic solvents, antibiotic resistance, weathering resistance, etc [38]. Moreover, PET resin has excellent formability that allows for the production of filaments having a variety of cross-sectional sizes and shapes by a melt spinning process [39]. For comparison with the fibrous assembly, a PET film with geometrical simplicity was chosen. The change in wettability on the PET surface due to the APPJ oxidation, APPJ coating and APPJ oxidation after APPJ coating are observed by the sessile drop method. The wettability is also evaluated by the Wilhelmy method, which can be applied to a single fiber to accurately measure the contact angles of water at the three-phase boundary [40]. Topographical and chemical changes on the PET surface due to the APPJ treatments are detected by surface analyses. We investigate the changes in textile-specific properties, such as antifouling, water wicking and dyeability due to the APPJ treatments using natural fiber, wool fabric, as well as the PET fabric.

\section{Fiber Surface Functionalization by Atmospheric Pressure Plasma Jet Treatments}

\subsection{APPJ treatments}

The APPJ oxidation was performed using a commercial apparatus (Plasmatreat $\mathrm{GmbH}$, Germany) consisting of a plasma generator (FG1001), a highvoltage transformer (HTR1001), and a rotating nozzle jet (RD1004). Herein, the operating voltage, current and frequency were $280 \mathrm{~V}, 6.0 \mathrm{~A}$ and $16 \mathrm{kHz}$, respectively. Nitrogen (99.99\%) was chosen as a reactive gas and its pressure and flow rate were regulated at $0.3 \mathrm{MPa}$ and $20 \mathrm{~L} / \mathrm{min}$, respectively [30]. The temperature of plasma jet was determined to be $100^{\circ} \mathrm{C}$ at exposure distance of $5 \mathrm{~mm}$ using $40 \mathrm{~mm} \phi$ nozzle [34].

A commercially available nanocoating equipment (Plasmatreat $\mathrm{GmbH}$, Germany) consisting of a plasma generator (FG 5001), a high-voltage transformer (HTR $12)$, a rotating nozzle jet (PFW 10-PAD) and a plasma polymer controller (PAD-1) was used for the APPJ coating [41, 42]. Nitrogen (99.99\%) was chosen as a reactive gas together with hexamethyldisiloxane (HMDSO, LS-7130, Shin-Estu) vapor as a precursor. The pressure and the flow rate of the nitrogen gas were regulated at $0.3 \mathrm{MPa}$ and $33.3 \mathrm{~L} / \mathrm{min}$, respectively, while the flow rate of the HMDSO was $0.66 \mathrm{~g} / \mathrm{min}$ [35]. The images of the nozzle jet during the APPJ treatments are shown in Fig. 1.

The surface characteristics of materials treated by the APPJ are strongly dependent on the processing parameters [26]. Therefore, the effects of the APPJ exposure conditions on the wettability of the treated PET surfaces were examined, wherein the optimum conditions were obtained (Table 1) [30, 33]. The conditions in Table 1 were used in all experiments herein.

\subsection{Change in wettability due to APPJ treatments}

The pure water drop images $2 \mathrm{~s}$ after placing on the PET film (Melinex ${ }^{\circledR}$, S-188, Teijin DuPont) and the PET fabric (taffeta, Japanese Standards Association), are presented in Fig. 2. The apparatus used was a video contact angle system (DSA $25 \mathrm{~S}$, KRÜSS GmbH, Germany). The contact angle, which was determined as an advancing because the liquid front of the water drop was observed to advance at $2 \mathrm{~s}$ [43], was also

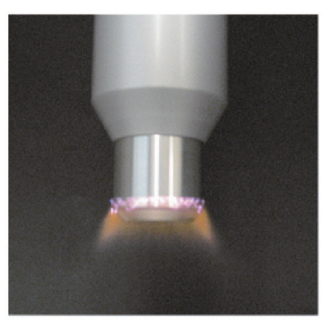

APPJ oxidation

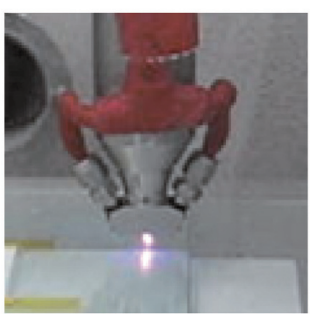

APPJ coating
Fig. 1 Images of plasma nozzle jet. 
Table 1 Experimental conditions of APPJ treatments.

\begin{tabular}{cccc}
\hline & \multicolumn{2}{c}{ APPJ-oxidation } & APPJ-coating \\
\cline { 2 - 3 } & \multicolumn{2}{c}{ Film } & Fabric \\
Reactive gas & \multicolumn{2}{c}{ Nitrogen } & Nitrogen \\
Precursor & \multicolumn{2}{c}{-} & HMDSO $\left(\mathrm{C}_{8} \mathrm{H}_{18} \mathrm{OSi}_{2}\right)$ \\
Nozzle diameter & $20 \mathrm{~mm}$ & $40 \mathrm{~mm}$ & $5 \mathrm{~mm}($ Feed pitch $3 \mathrm{~mm})$ \\
Exposure distance & $7 \mathrm{~mm}$ & $5 \mathrm{~mm}$ & $15 \mathrm{~mm}$ \\
Moving velocity & \multicolumn{2}{c}{$10 \mathrm{~m} / \mathrm{min}$} & $20 \mathrm{~m} / \mathrm{min}$ \\
\hline
\end{tabular}

inserted in Fig. 2.

In both the cases of the PET film and PET fabric, the APPJ oxidation provided hydrophilic properties to their surfaces. After the APPJ coating, the PET surfaces showed superior water repellency. When the APPJ-coated PET surfaces were subsequently treated by the APPJ oxidation (APPJ coating/APPJ oxidation), super-hydrophilization was observed [37, 44].

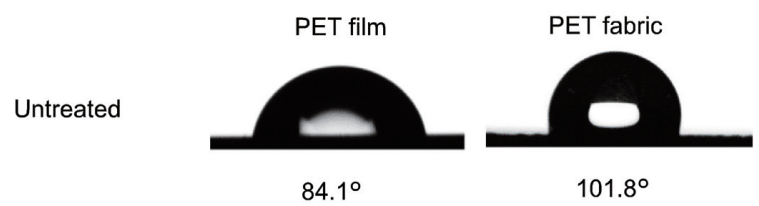

APPJ oxidation

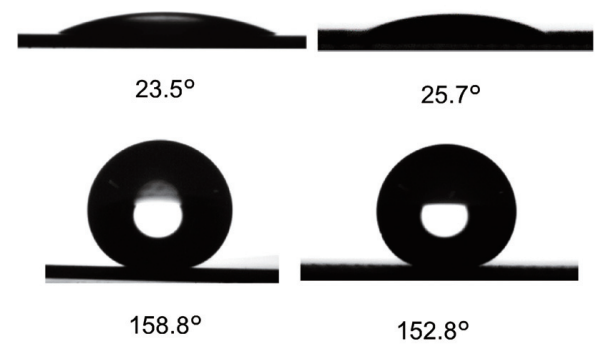

APPJ coating IAPPJ oxidation

$8.6^{\circ}$

$7.2^{\circ}$

Fig. 2 Water drop image and contact angles (corresponding to the advancing angles) on PET films and PET fabrics untreated and treated by the APPJ.

\subsection{Effect of aging time on wettability after APPJ treatments}

The water contact angle of polymer surfaces hydrophilized by dry gas-phase oxidation gradually increases after the treatment. This is called "hydrophobic recovery", which occurs due to the loss of volatile oxidized species to the atmosphere, as well as the reorientation and migration of polymer chains in the polymer surface layer [45-50]. Therefore, the changes in the contact angles on the PET sample after the APPJ treatments with aging time were investigated (Fig. 3) [36, 37]. Expectedly, the contact angles on the PET film gradually increased after the APPJ oxidation and remained almost constant after one to two weeks. Such low wettability stabilities after the APPJ oxidation portend a serious problem for their application to polymer surface functionalization. In contrast, the PET film and PET fiber surfaces treated by the APPJ coating maintained superior water repellency for at least over two weeks. The APPJ-coated PET surfaces treated by APPJ oxidation also sustained their super-
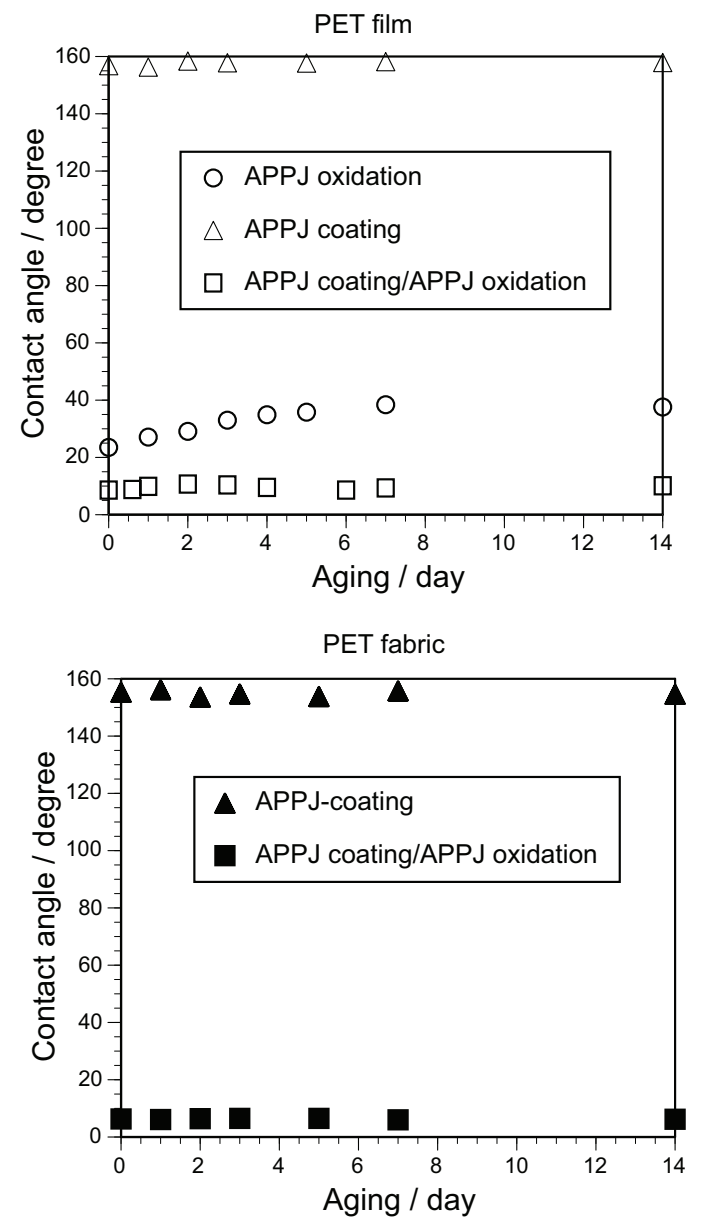

Fig. 3 Change in sessile drop contact angle of water on PET films and PET fabrics after APPJ treatments with aging time in air. 
hydrophilicity. Such high wettability stability may be associated with the surface molecular structure of the APPJ-coated PET. Generally, hydrophilic surfaces with large surface free energies are prone to contamination and becomes hydrophobic [51]. From this perspective, it is remarkable that the combination of APPJ coating and APPJ oxidation makes it possible to construct stable high-energy surfaces.

\subsection{Wettability evaluation by the wetting force measurement}

The contact angle obtained by the sessile drop method is an apparent value, not an accurate angle at the PET/water/air three-phase boundary [52]. For a single fiber, the contact angle cannot be measured by the sessile drop method. However, the Wilhelmy method, which can be applied to a single fiber, is not only an ideal method for obtaining high-precision contact angles but also an approach that enables the attainment a thermodynamically significant Young contact angle at three-phase boundaries [33, 53, 54].

For the wetting force measurement by the Wilhelmy method, a high-performance force tensiometer (Sigma 701, Biolin Scientific) with a balance resolution of $1 \mu \mathrm{N}$ was used for the PET film sample. In the single fiber sample, an equipment consisting of an electrobalance (Model C-2000, Cahn Instruments Inc., USA) with a balance resolution of $0.1 \mu \mathrm{N}$ and a reversible elevator (MP-20 L, MICOS, Germany) were chosen. Fig. 4 shows the experimental set-up for the wetting force measurements. A PET film strip or a PET single fiber taken from the PET fabric that was suspended from the electrobalance

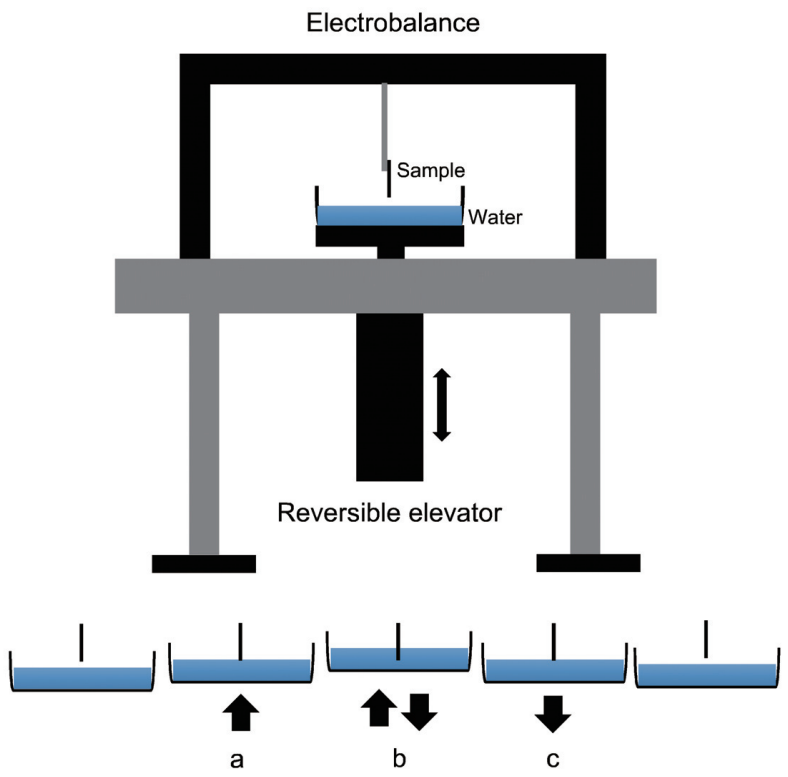

Fig. 4 Apparatus for wetting force measurement by the Wilhelmy method. arm. Below the sample, a glass vessel containing water was placed on a stage connected to the reversible elevator. The water surface was raised until 10-12 mm (film) or 2-3 mm (fiber) of the lower part of the sample was immersed (points “a” indicates the moment when the water surface touched the bottom of the sample). The water surface was moved down (point "b") until the surface separated from the bottom of the fiber (point "c"). The force was continuously recorded during an immersionwithdrawal cycle at an interfacial moving velocity of $0.3 \mathrm{~mm} / \mathrm{min}$, which yielded a thermodynamically significant contact angle [54, 55].

Typical force recordings obtained for the PET film and PET fiber are illustrated in Figs. 5 and 6, respectively $[36,37,56]$. The changes in the force at the points "a" and " $\mathrm{c}$ " correspond to the advancing and receding wetting forces, respectively, from which the advancing and receding contact angles, $\theta_{\mathrm{a}}$ and $\theta_{\mathrm{r}}$, respectively, were calculated by the Wilhelmy

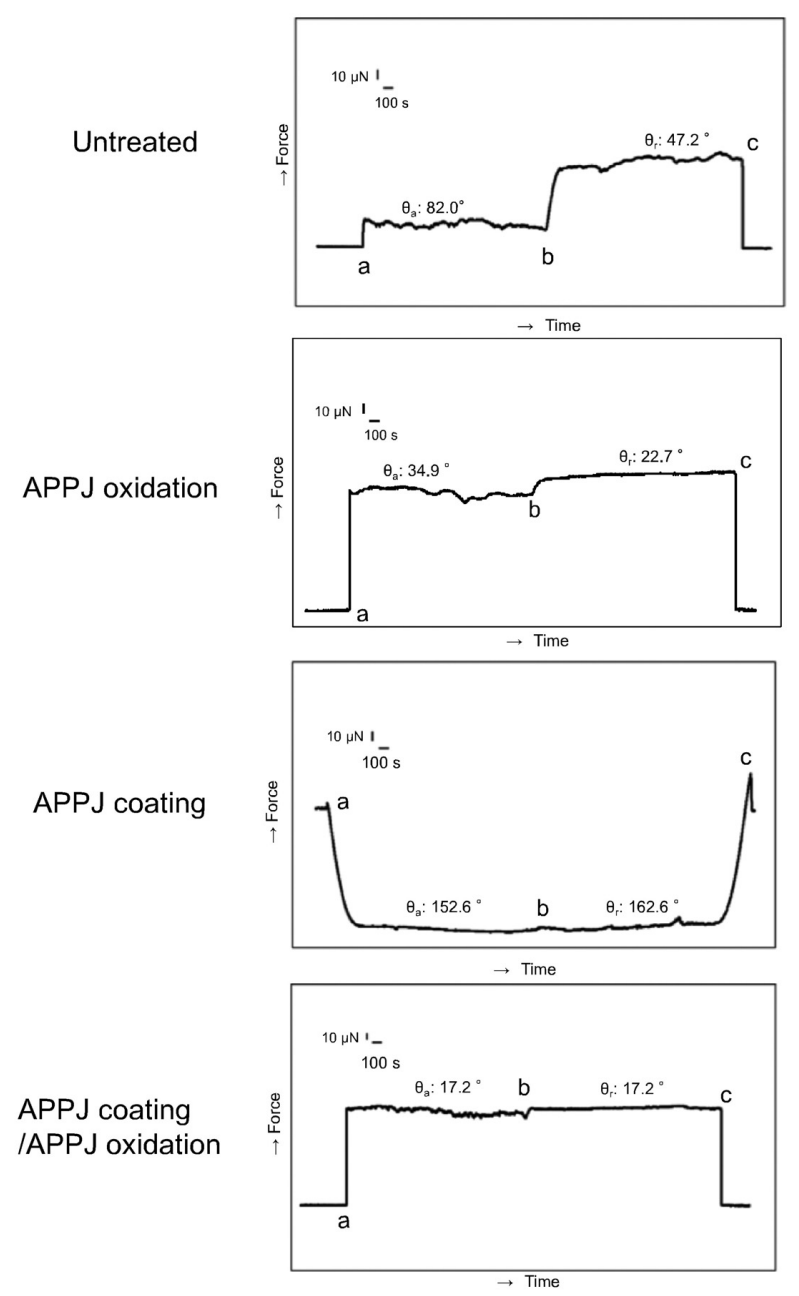

Fig. 5 Typical force recordings of PET films untreated and treated by the APPJ obtained by the Wilhelmy method and the calculated advancing $\left(\theta_{\mathrm{a}}\right)$ and receding $\left(\theta_{\mathrm{r}}\right)$ contact angles. 

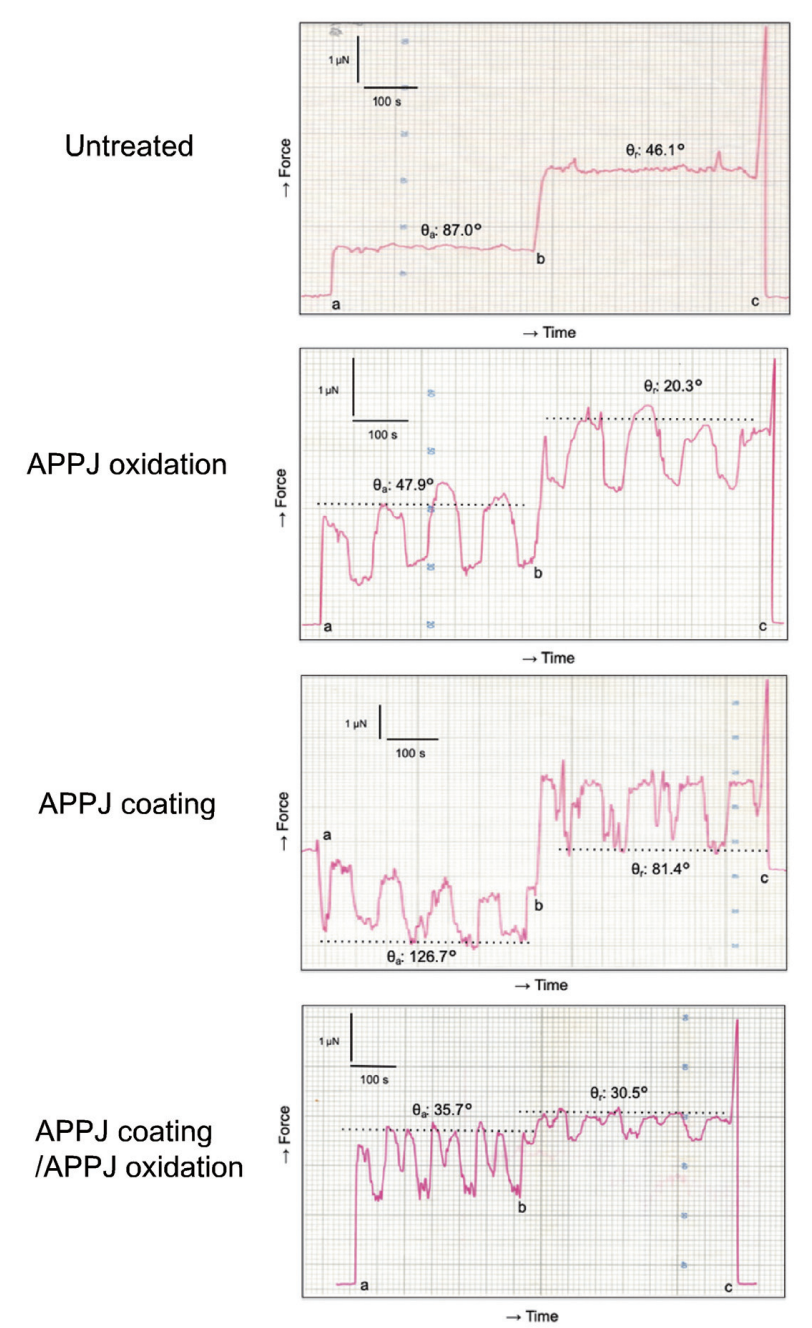

Fig. 6 Typical force recordings of PET fibers untreated and treated by the APPJ obtained by the Wilhelmy method and the calculated advancing $\left(\theta_{\mathrm{a}}\right)$ and receding $\left(\theta_{\mathrm{r}}\right)$ contact angles.

relation [57]. For the PET film, the forces during the advancing and receding scans were almost constant. However, periodic force changes were observed in the advancing and receding scans for the APPJtreated PET fibers, suggesting that the water contact angles periodically changed along the fiber axis. The periodicity of the force recording in Fig. 6 is consistent with that of crimping in the fiber due to the weaving of the fabric. The penetration depth of the active species generated in the plasma jet into the fibrous assembly may affect the wettability of the treated fiber surface [58-60]. Therefore, as the advancing and receding contact angles on a sufficiently treated region on the fiber surface, the contact angles (minimum contact angles) after APPJ oxidation and APPJ coating /APPJ oxidation were calculated from the maximum wetting forces. On the other hand, the contact angles after APPJ coating (maximum contact angles) were calculated from the minimum wetting forces.

In cases of both the PET film and PET fiber, the contact angles decreased and increased after APPJ oxidation and APPJ coating, respectively. The subsequent APPJ oxidation after APPJ coating remarkably decreased the contact angle. The same tendency was observed for the advancing contact angles obtained by the sessile drop method (see Fig. 2), but the absolute values were different. It has been reported that the roughness and geometry of the sample surfaces had effects on the contact angles determined by the sessile drop method [61]. On the other hand, the contact angle measured by the Wilhelmy method is corresponding to an intrinsic angle at the three-phase boundary [62]. Therefore, the difference in the obtained advancing contact angles between the sessile drop and the Wilhelmy methods is due to surface roughness.

Surprisingly, the advancing and receding contact angles on the PET film after APPJ coating and APPJ coating /APPJ oxidation were of the same value, i.e. no contact angle hysteresis was observed (see Fig. 5). A real surface is commonly heterogeneous, which causes contact angle hysteresis [63,64]. The results in Fig. 5 indicate that the APPJ-coated films, with and without APPJ oxidation, are homogenous surfaces

\subsection{Surface topographical and chemical changes due to APPJ treatments}

Figs. 7 and 8 show the scanning electron microscopy (SEM) images of the PET films [31] and PET fibers [36, 56], respectively, before and after the APPJ-treatment. For both samples, the surfaces after the APPJ oxidation were also found to be as smooth as the untreated surfaces. However, after APPJ coating, the surface morphology became granular. Similar results have been reported for plasma polymerization using HMDSO [65-69] The granular morphology of the APPJ-coated PET surface was almost maintained after the subsequent APPJ oxidation.

Fig. 9 reveals the cross-sectional SEM image of the APPJ coating deposited on the copper substrate, which was chosen due to the contrast enhancement of the SEM observation between the coating film and the substrate [37]. It is discovered that the APPJcoated film composed of two layers. The lower layer is densely packed with a thickness of approximately $100 \mathrm{~nm}$, while the upper layer consists of granular particles.

The atomic force microscopy (AFM) images of 


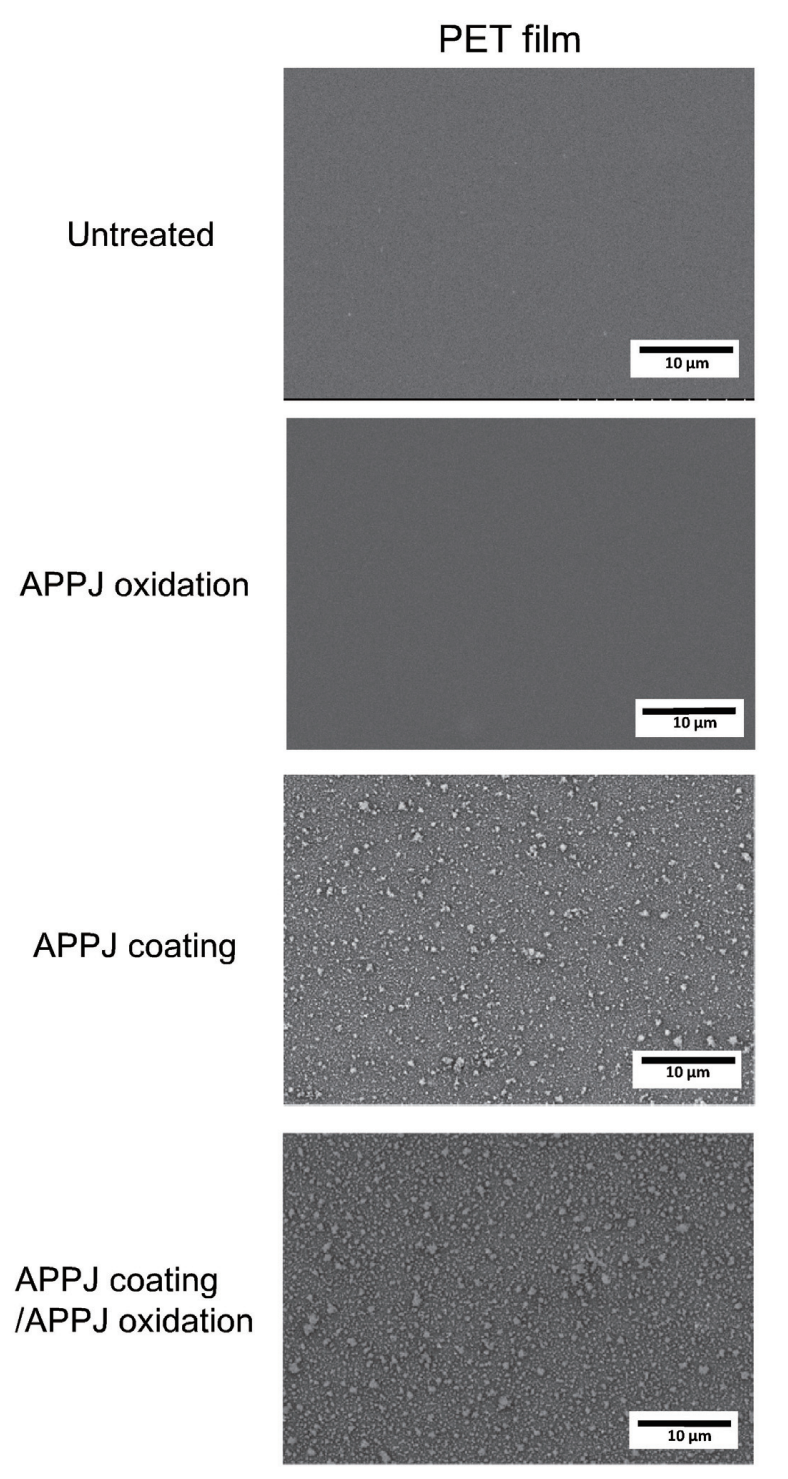

Fig. 7 SEM images of PET films untreated and treated by the APPJ.

the untreated and APPJ-oxidized PET films [32] and PET fibers [33], which are seen to be smooth by the SEM observation on a micrometer scale, are presented in Fig. 10. The untreated film and fiber are discovered to be smooth on a nanometer scale (Figs. 7 and 8). The APPJ oxidation can cause ablation of the surfaces of the PET film and fiber, resulting in surface topographical change at the nanometer scale.

The surface atomic compositions obtained from high resolution X-ray photoelectron spectroscopy (XPS) are summarized in Fig. 11. The changes in atomic composition due to the APPJ treatments had similar tendencies between the PET film and PET fabric. The results indicate that oxygen atoms, not nitrogen atoms, were incorporated into the PET surface by APPJ oxidation using nitrogen as the reactive gas. In the previous paper [32], the APPJ oxidation of the PET film surface with nitrogen gas

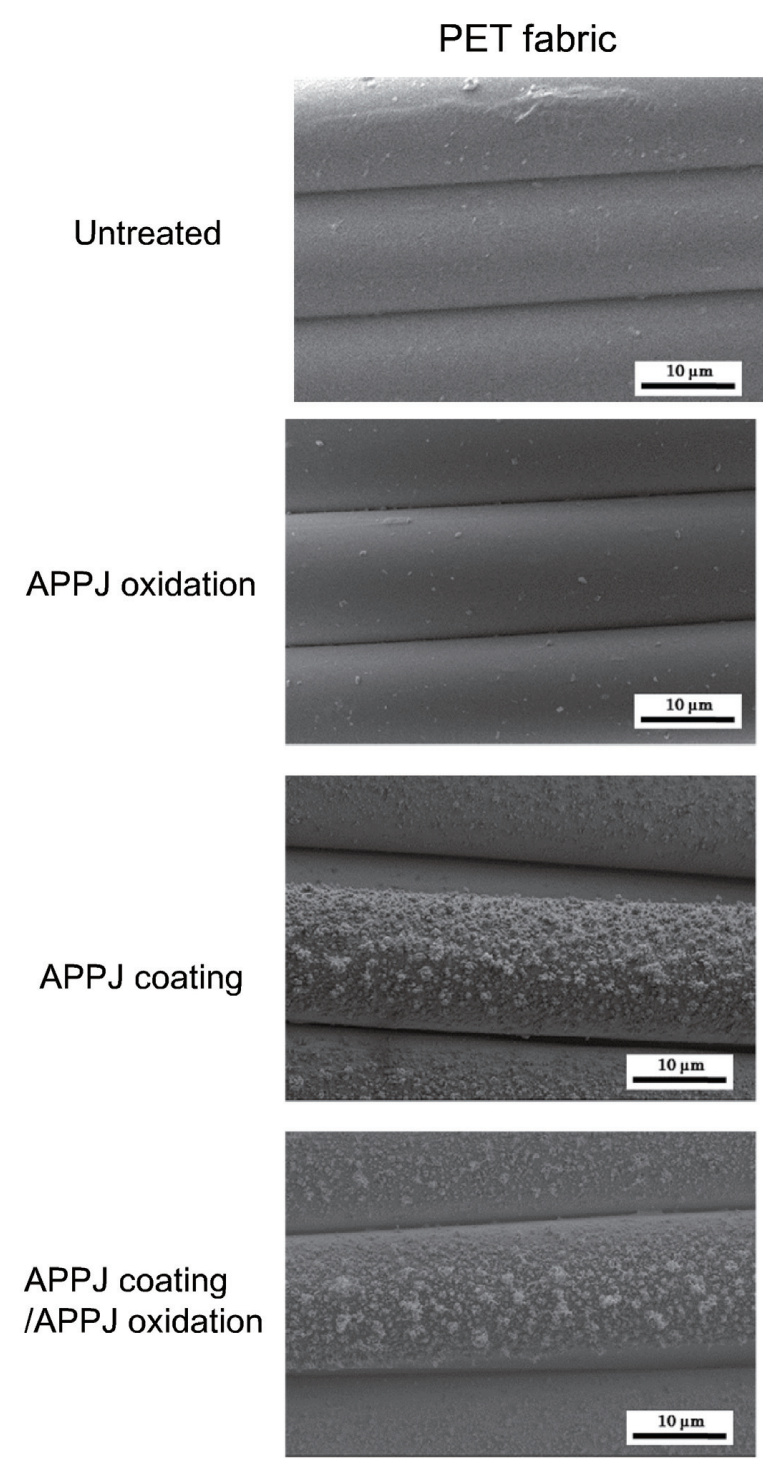

Fig. 8 SEM images of PET fabrics untreated and treated by the APPJ.

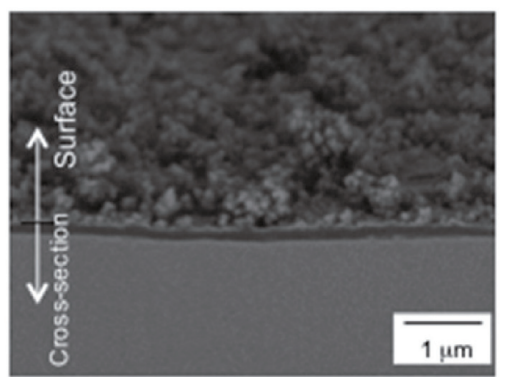

Fig. 9 SEM image of surface and cross-section of PET film treated by the APPJ coating.

was performed at various exposure distances. Although the oxygen concentrations after the APPJ oxidation were almost the same, the nitrogen concentration was found to increase with decreasing exposure distance. Therefore, it was concluded that the plasma-surface reaction can enhance in the vicinity of the nozzle jet. This experimental finding suggests that the activation mechanism by the APPJ 


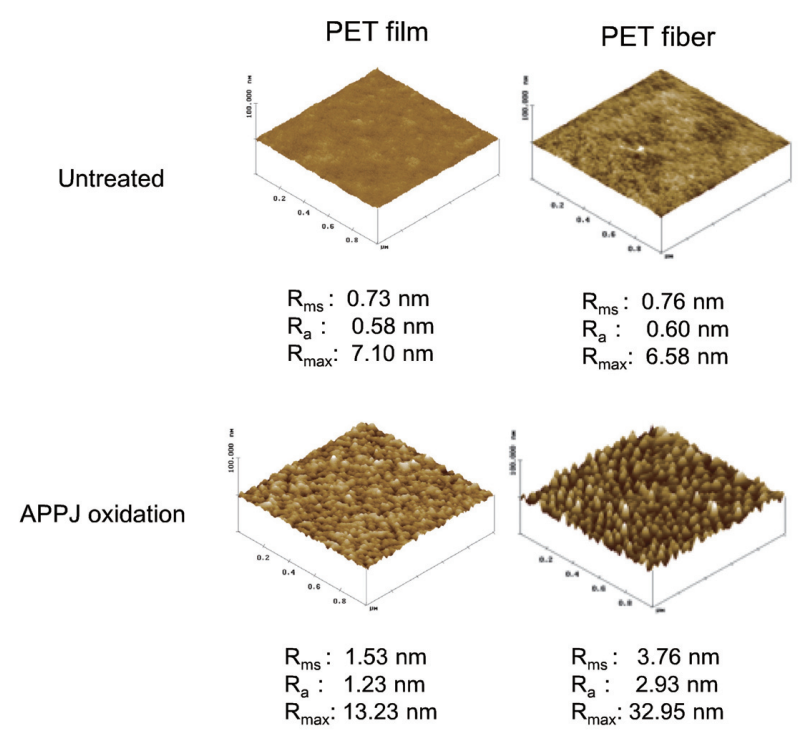

Fig. 10 AFM images of PET films and PET fibers untreated and treated by the APPJ oxidation.

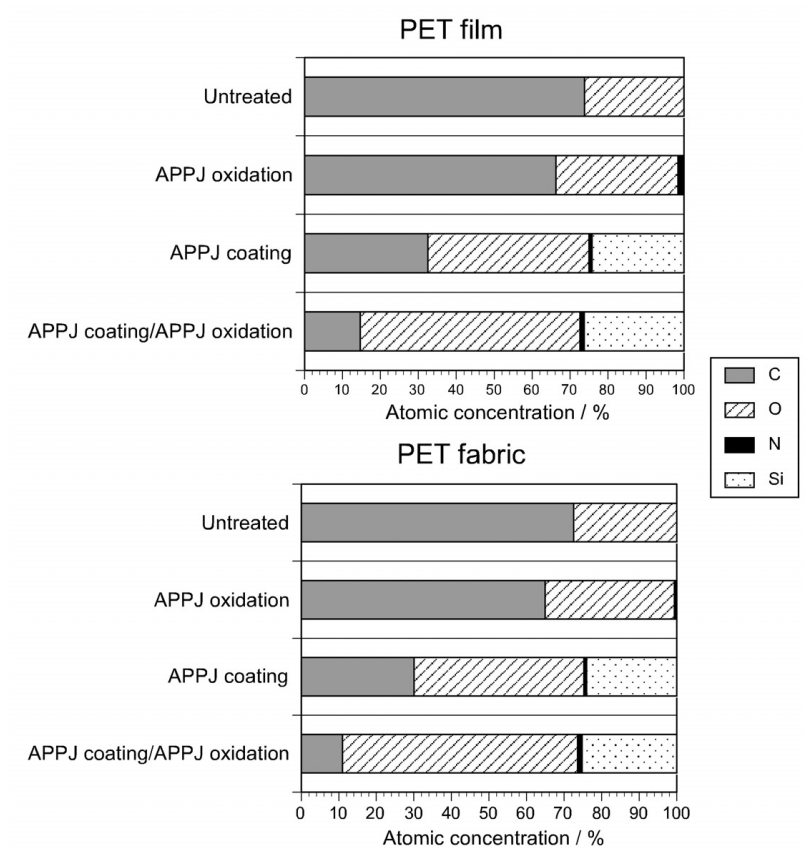

Fig. 11 Surface atomic concentrations on PET films and PET fabrics untreated and treated by the APPJ obtained by XPS analysis.

is not only a plasma-surface interaction but also a post-plasma processes, wherein the oxygen or water vapor that diffuses into the plasma jet is incorporated into the polymer surface [70]. We have previously reported that the oxidation of the PET film treated with the APPJ leads to the formation of oxygencontaining functional groups [35]. After the APPJ coating, the amount of silicon detected was approximately half of the amount of oxygen for both film and fiber, indicating that an $\mathrm{SiO}_{2}$ film was deposited on the surfaces [71-74]. However, the carbon content on the outermost layer of the APPJ-

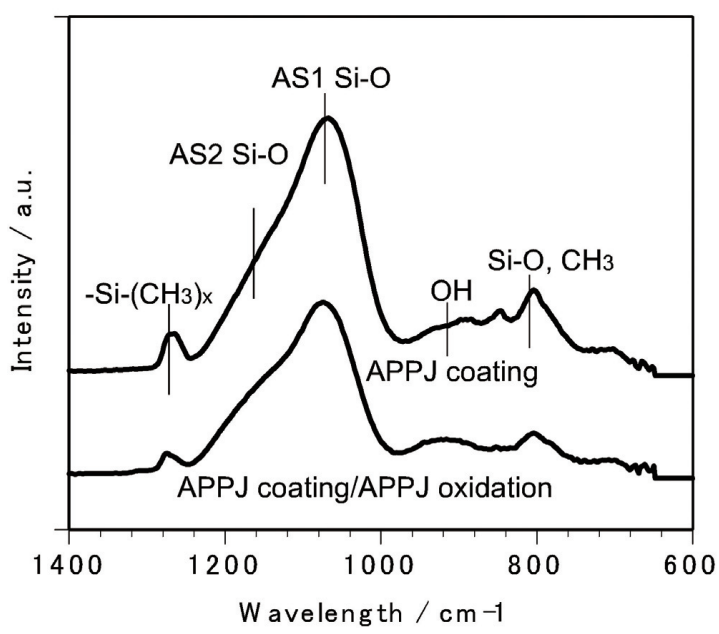

Fig. 12 Normalized GATR-FTIR spectra of PET films treated by APPJ coating and APPJ coating/APPJ oxidation.

coated film is approximately $30 \%$, and therefore, the terminal $\mathrm{CH}_{3}$ group will remain on the as-depositcoated PET surface. After the subsequent APPJ oxidation, the carbon concentration decreased, while the oxygen-to-silicon ratio remained the same.

Fig.12 shows the Frourier transform infarad (GATR-FTIR) spectra normalized by maximum peaks of approximately $1075 \mathrm{~cm}^{-1}$ for the APPJ-coated PET films with and without APPJ oxidation [37]. For the APPJ coating, the absorption peaks corresponding to the asymmetric stretching mode at the 1000-1200 $\mathrm{cm}^{-1}$ region and the bending mode at $804 \mathrm{~cm}^{-1}$ are visible. The absorption peaks associated with the Si$\left(\mathrm{CH}_{3}\right)_{\mathrm{x}}$ bending mode at $1265 \mathrm{~cm}^{-1}$ are also clearly observed. It has been reported $[75,76]$ that the carbon content of $\mathrm{SiO}_{2}$-like films from HMDSO deposited using the APPJ is strongly dependent on the HMDSO flow rate. At a high flow rate, carbon is comprised in the films deposited by the APPJ treatment. Consequently, the high flow rate of HMDSO leads to $\mathrm{SiO}_{2}$-like films with carbon content. Similar spectrum patterns were observed on the APPJ-coated film, and therefore, polymerization of HMDSO may progress until large $\left(\mathrm{SiO}_{2}\right)_{\mathrm{x}}$ macromolecules consisting of $\mathrm{SiO}_{2}$ subunits with terminal $\mathrm{CH}_{3}$ groups are formed.

After the subsequent APPJ oxidation, the intensity of the carbon-related peak at $1265 \mathrm{~cm}^{-1}$ is marginally decreased, indicating that the bulk composition of the coating films is not changed. 


\section{Textile Performances Introduced by Atmospheric Pressure Plasma Jet Treatments}

\subsection{Improvement of antifouling properties by APPJ treatments}

In a daily life, antifouling properties of textiles are desired to maintain the appearance and performance of the apparel. According to the work of adhesion [77], making the fiber surfaces hydrophobic can result in good soil guard performance. Contrarily, the surface hydrophilization can improve soil removal by laundering. Therefore, wettability control by the APPJ can apply antifouling properties to textiles. The deposition of particulate soils on the PET fabric in air was investigated in reference to JIS L1919, A-1 [35, 56, 78]. A polyethylene cylindrical bottle $(90 \mathrm{~mm} \phi \times 190$ $\mathrm{mm})$, containing the untreated and the APPJ-treated fabrics ( $40 \mathrm{~mm} \times 40 \mathrm{~mm}$, total four samples) and the model particulate soil, $0.01 \mathrm{~g}$ carbon black (model soot) or $0.10 \mathrm{~g}$ colored Lycopodium (model cedar pollen), was rotated at $60 \mathrm{rpm}$ for $20 \mathrm{~min}$. The deposition experiments were performed in a room maintained at $20{ }^{\circ} \mathrm{C}$ and $65 \%$ RH. Soil deposition onto the PET fabric was observed by a biological microscope. The images of the PET fabric are given in Fig. 13 [36]. For both soils, the deposition was expectedly prevented after the hydrophobization by the APPJ coating, which was unaffected by the remarkable hydrophilization by the subsequent APPJ oxidation. In the previous paper [44], we compared antifouling properties between the PET fabrics treated with the APPJ coating and the fluorine-based agent. The APPJ coating produced superior antifouling properties in comparison with the fluorine-based agent, which was not associated with static electricity. It is believed that the reduction in the contact region between the substrate and soil due to granular morphology improved antifouling properties [79-81].

As a measure of the amount of soil deposited on the fabric, the surface reflectance, $\mathrm{R}$, on each side of the fabric was read at a wavelength of $460 \mathrm{~nm}$ for carbon black and $560 \mathrm{~nm}$ for Lycopodium using a high-precision spectrophotometer, whereof the Kubelka-Munk function value, $\mathrm{K} / \mathrm{S}$ (i.e., $\mathrm{K} / \mathrm{S}=(1-\mathrm{R})^{2} /$ $2 \mathrm{R})$, was calculated [82]. The results are given in Fig. 14 (upper figure) [36], and the $\mathrm{K} / \mathrm{S}$ values do not contradict the image in Fig. 13.

After evaluating the $\mathrm{K} / \mathrm{S}$ value, the soiled fabric was immersed perpendicularly into an aqueous

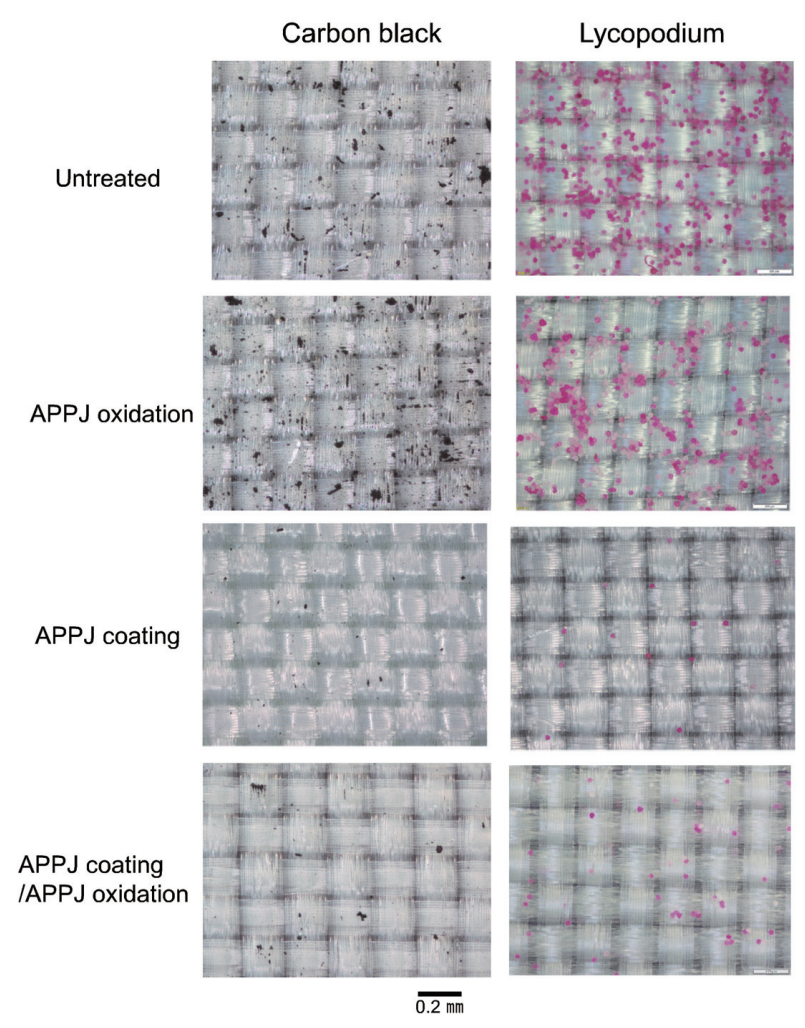

Fig. 13 Images of PET fabrics untreated and treated by the APPJ after soil deposition in air.
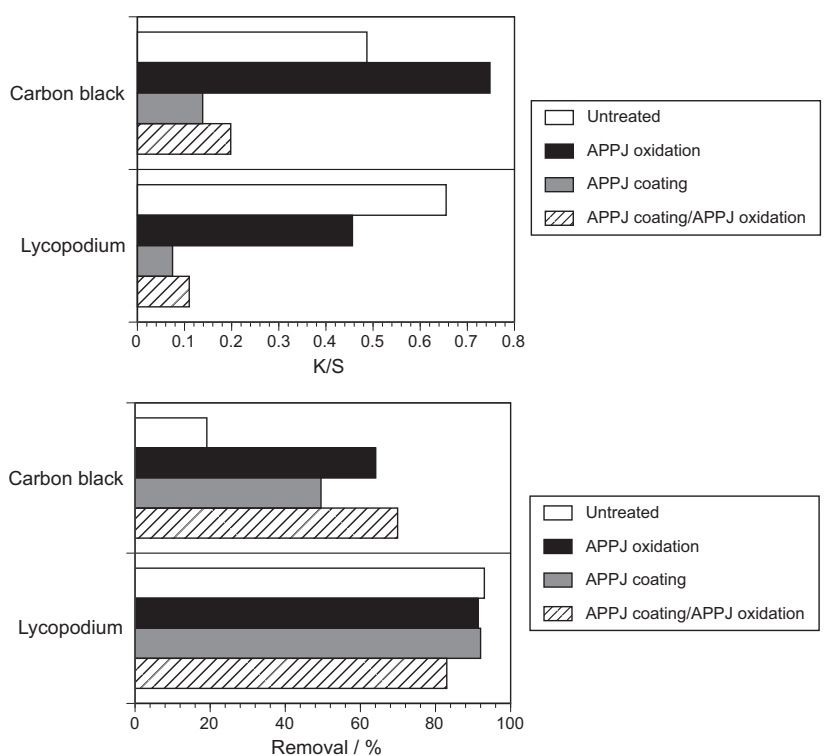

Fig. 14 The Kubelka-Munk function, K/S, of PET fabrics untreated and treated by the APPJ after soil deposition in air and the soil removal due to cleaning in the aqueous surfactant solution.

solution containing $0.14 \mathrm{mmol} / \mathrm{dm}^{3}$ alcohol ethoxylates (nonionic surfactant) with stirring as a mechanical action for soil removal. After cleaning for $5 \mathrm{~min}$ at $25^{\circ} \mathrm{C}$, the fabric was removed from the solution and dried, and then the K/S of the PET fabric after cleaning was measured. The soil removal efficiency was calculated from the $\mathrm{K} / \mathrm{S}$ values of the fabrics before and after 
the cleaning and that of the original fabric [83]. The obtained removal efficiency is given in Fig. 14 (lower figure) [36]. Lycopodium with a diameter of tens of micrometers was easily removed from any fabric. For carbon black, the hydrophilization of the PET fabric (APPJ oxidation and APPJ coating/APPJ oxidation) makes it possible to promote soil release. Unexpectedly, the hydrophobization by the APPJ coating did not so much decreased the soil removal.

The changes in soil deposition and removal due to the APPJ treatment in Figs. 13 and 14 shows that the antifouling properties are dominated not only by the surface wettability but also by the surface topography.

\subsection{Provision of water absorbency by APPJ treatments}

The hydrophobic PET fabric is difficult to wet by water. The effect of the fiber surface hydrophilization by the APPJ oxidation on water absorbency was evaluated. As a measure of water absorbency, the vertical wicking height into the capillaries of the PET fabric was measured as a function of time in reference to JIS L 1907 [84]. A fabric strip with a $20 \mathrm{~mm}$ width and a $150 \mathrm{~mm}$ length was hung vertically and its
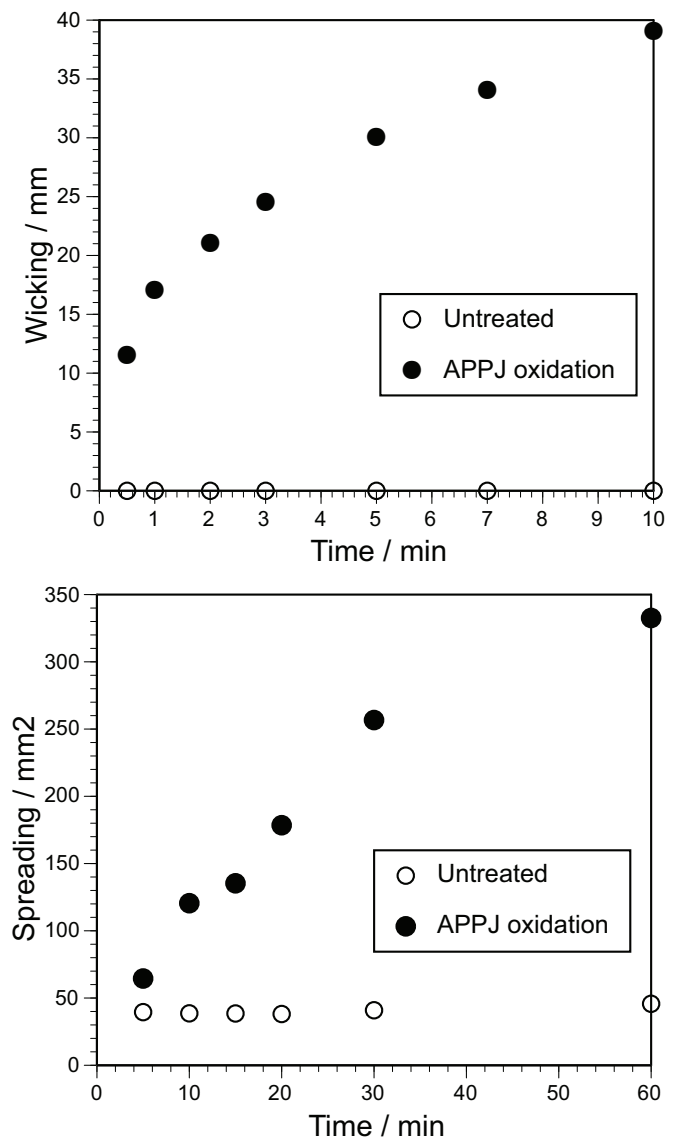

Fig. 15 Changes in wicking height and spreading area of water penetrated into PET fabrics untreated and treated by the APPJ oxidation. lower end was dipped into water. The height of rise of the liquid at the center of the strip above the water level was measured as a function of time.

On the other hand, the horizontal wicking of water in the PET fabric was observed as spreading of water [34]. A drop of water was placed on the fabric and photographs were taken at given times. The spreading area on the fabric was determined by binary processing using a 2D image analysis software. The photograph of the fabric was converted from the original grayscale digital image with 256 possible intensity values to a binary one.

The results are given in Fig. 15 [34]. As is expected, no wicking and spreading of water were observed for the untreated PET fabrics. After APPJ oxidation, the water wicking and spreading were remarkably enhanced. This result may be caused by the decrease in the advancing contact angle of water on the fiber surfaces (Fig. 6), deduced from the Washburn equation [85].

Among natural fibers, the wool fabric is known to be hydrophobic. The effect of the APPJ oxidation on water absorbency of wool fabric (plain, Japanese
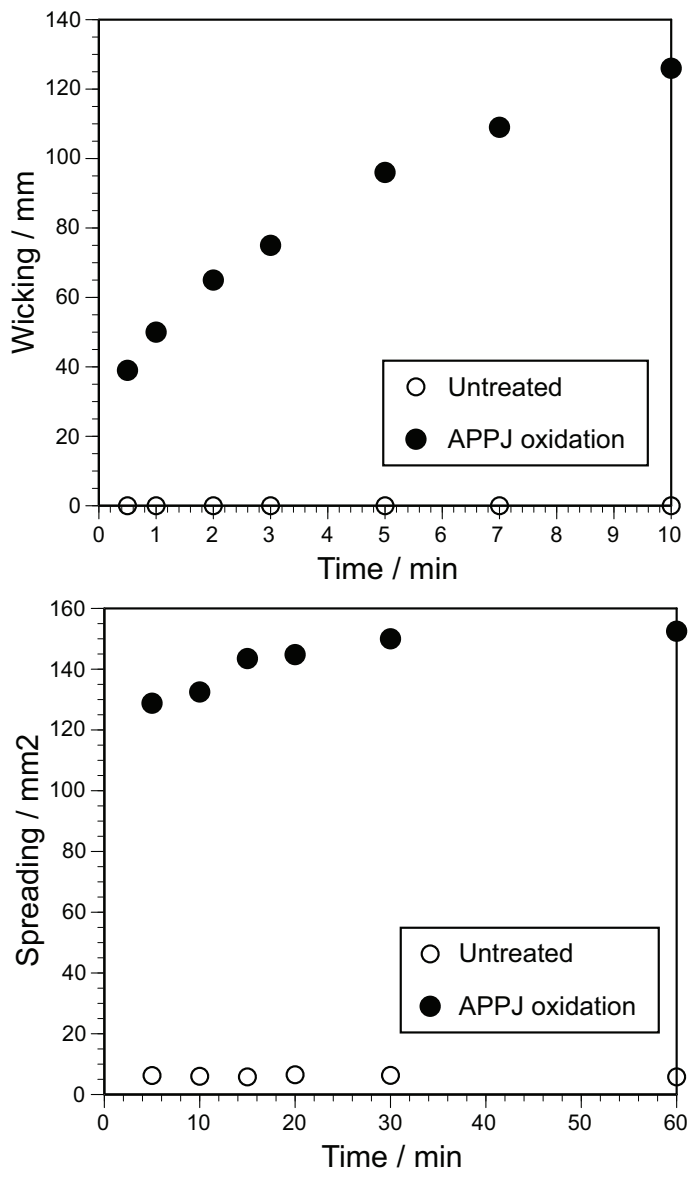

Fig. 16 Changes in wicking height and spreading area of water penetrated into wool fabrics untreated and treated by the APPJ oxidation. 
Standards Association) was also investigated (Fig. 16) [86]. No wicking and spreading were observed for untreated wool fabric, because of water repellency of wool fiber surface. After APPJ oxidation, the highlevel water absorbency was obtained. The APPJ oxidation may affect the quick-drying, which is one of the remarkable properties of wool fabric. The weight of the wool fabric after being wetted was monitored and the calculated moisture content was plotted as a function of time. The results are presented in Fig. 17 [86]. The shape of the curves obtained before and after the APPJ oxidation was similar, and the time required for drying was almost the same ( $\sim 80 \mathrm{~min})$, although a slight increment in moisture content was found after APPJ oxidation. Therefore, the APPJ oxidation of wool fabric promotes its water absorbency, but does not reduce its quick-drying property.

\subsection{Dyeability improvement by APPJ oxidation pre- treatment}

Fig. 18 (upper figures) shows the image of the untreated and the APPJ-oxidized PET fabrics after dip dyeing with three dispersive dyes. The $\mathrm{K} / \mathrm{S}$ value, as measure of the color strength of a fabric surface, is given in Fig. 18 (lower figure) [34]. The K/S values were high for the PET fabric oxidized by the APPJ pre-treatment compared with the untreated fabric in all cases of dye. The uptake of dispersive dyes is commonly independent of the existence of surface functional groups. Therefore, the change in dyeing behavior due to the APPJ oxidation, i.e., the deeper coloring, may be caused primarily by increased light

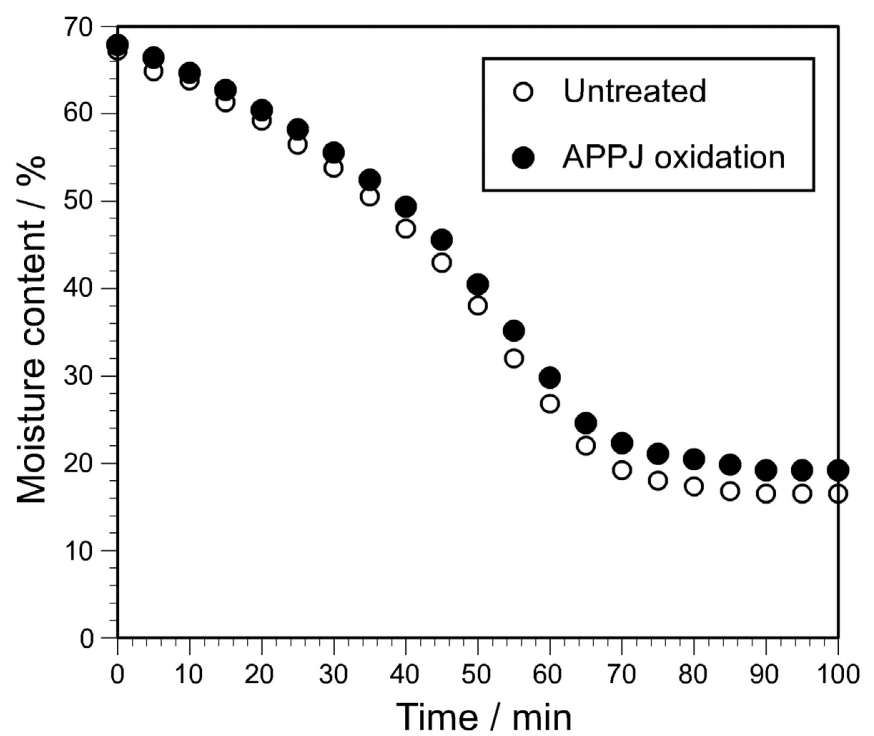

Fig. 17 Change in moisture content of wetted wool fabrics untreated and treated by the APPJ oxidation with drying time.
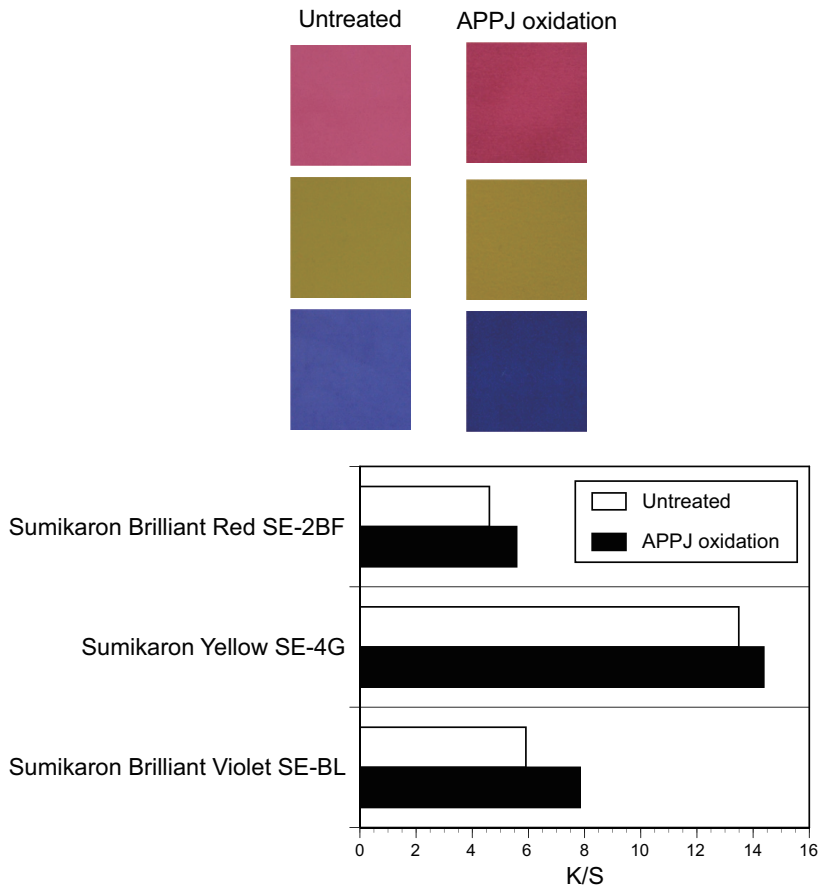

Fig. 18 Images of PET fabrics untreated and treated by the APPJ oxidation after dyeing with three dispersive dyes (upper) and their K/S value (lower).

scattering due to the nanoscale roughness of the fiber surfaces as shown in Fig. 10 [87]. Additionally, the increased wettability of the single fiber surface may enhance the dye uptake of the fabric [87, 88]. The above experimental results indicate that the APPJ treatment improves the dyeability of PET fabrics
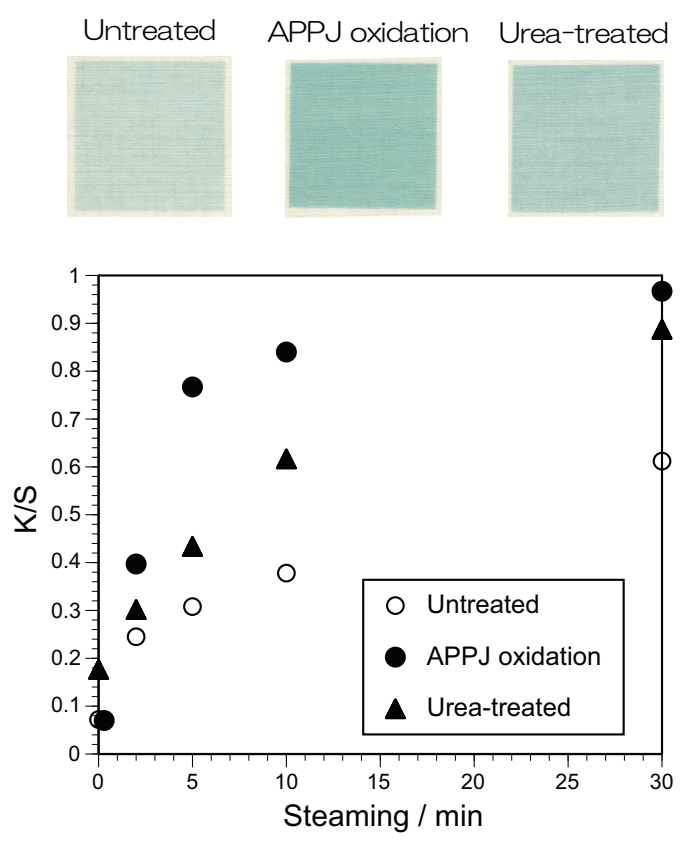

Fig. 19 Images of wool fabrics untreated and treated by the APPJ oxidation after ink-jet dyeing with acid dye (Acid Green 27, steaming time of $5 \mathrm{~min}$ ) (upper) and their $\mathrm{K} / \mathrm{S}$ value as a function of steaming time (lower). 
with dispersive dyes.

Instead of dip dyeing, ink-jet dyeing has developed rapidly in recent years, because it is suitable for short runs, small batches, and "just-intime" production. Ink-jet dyeing of the wool fabric with an acid dye (Acid Green 27, milling type) was carried out. As a pre-treatment of printing, APPJ oxidation was attempted in comparison with chemicals containing urea and sizing agents. After printing, the wool fabric was steamed. The images of the dyed fabric and the obtained values of $\mathrm{K} / \mathrm{S}$ are shown in Fig. 19 [86]. For short steaming times, the K/S value, as a measure of the deeper coloring, largely increased with the pre-treatment by APPJ oxidation compared with the chemical treatment. It was confirmed from image analysis that the APPJ oxidation did not cause bleeding and uneven dyeing. The color fastness of the dyed fabric to washing and rubbing did not reduce due to the pre-treatments by the APPJ or chemicals [89]. We believe that the introduction of the APPJ pre-treatment to the ink-jet dyeing is effective to reduce negative environmental impacts, while improving the energy efficiency and productivity of the dyeing process.

\section{Conclusions}

The two APPJ treatments achieved surface alteration, such as hydrophilization, hydrophobization and roughening, without modifying the bulk properties of textile materials. The high precision control of the wettability of textiles and fiber surfaces makes it possible to generate high performances regarding antifouling, water absorbency and dyeability. Recently, fiber composite materials, such as fiber-reinforced plastic, are often used in industrial products. Conductive fibers and yarns for smart textiles have also been considered in the production process of smart textiles. Herein, to increase adhesion to other materials, the control of the wettability of the fiber surfaces, is of importance. Furthermore, the APPJ treatment enables high-speed continuous in-line material processing in ambient air, as well as being environment- and worker-friendly. It is noteworthy that the two APPJ treatments can create highly stable and homogeneous surfaces. Both treatments will be applied as a next generation technology to produce high-performance textiles such as smart textiles.

\section{Acknowlegements}

I am grateful to the Ministry of Education, Sports, Culture, Science and Technology, Japan for a Grantin-Aid for Scientific Research to carry out this work. Collaborations with coauthors of cited papers and students in my laboratories are highly appreciated.

\section{References and Citations}

1. O. V. Mikhailova, N. N. Pavlov, V. M. Barantsev, and S. V. Degtyarev, Fibre Chem., 40, 107-109 (2008).

2. D. Enescu, Romanian Biotechnological Letters, 13, 4037-4048 (2008).

3. J. Wang and J. Liu, "Surface modification of textiles by aqueous solutions”, in: Surface Modification of Textiles (Q. Wei Ed.), CRC Press, Boca Raton, FL, pp. 269-295 (2009).

4. M. M. B. Hasan, A. Calvimontes, and V. Dutschk, J. Surfactants Detergents, 12, 285-294 (2009).

5. K. Opwis and J. S. Gutmann, Textile Res. J., 81, 1594-1602 (2011).

6. S. Luo and W. J. van Ooij, J. Adhesion Sci. Technol., 16, 1715-1735 (2012).

7. P. Sophonvachiraporn, R. Rujiravanit, T. Sreethawong, S. Tokura, and S. Chavadej, Plasma Chem Plasma Process, 31, 2233-249 (2011).

8. T. Okuno, T. Yasuda, and H. Yasuda, Textile Res. J., 62, 474-480 (1992).

9. H. Höcker, Pure Appl. Chem. 74, 423-427 (2002).

10. D. Sun and G. K. Stylios, Textile Res. J., 75, 639-644 (2005).

11. C. W. Kan and C. W. Yuen, Textile Res. J., 76, 309_ 314 (2006).

12. M. Mori and N. Inagaki, Textile Res. J., 79, 687-694 (2006).

13. C. W. Kan, Fibers Polymers, 8, 629-634 (2007).

14. J. Verschuren, P. Kiekens, and C. Leys, Textile Res. J., 77, 727-733 (2007).

15. C. Canal, P. Erra, R. Molina, and E. Bertrán, Textile Res. J., 77, 559-564 (2007).

16. K. N. Pandiyaraj and V. Selvarajan, J. Mater. Process Technol., 199, 130-139 (2008).

17. R. Morent, N. De Geyter, J. Verschuren, K. De Clerck, P. Kiekens, and C. Leys, Surface Coatings Technol., 202, 3427-3449 (2008).

18. Z. Cai, Y. Qiu, C. Zhang, Y. -J.Hwang, and M. McCord, Textile Res. J., 73, 670-674 (2003).

19. A. Schütze, J. Y. Jeong, S. E. Babayan, J. Park, G. S. 
Selwyn, and R. F. Hicks, IEEE Trans. Plasma Sci., 26, 1685-1694 (1998).

20. S. Förster, C. Mohr, and W. Viöl, Surface Coatings Technol., 200, 827-830 (2005).

21. X. Lu and M. Laroussi, J. Appl. Phys., 100, 063302 (2006).

22. M. Laroussi and T. Akan, Plasma Process. Polym. 4, 777-788 (2007).

23. X. Lu, Q. Xiong, Z. Xiong, J. Hu, F. Zhou, W. Gong, Y. Xian, C. Zou, Z. Tang, Z. Jiang, and Y. Pan, J. Appl. Phys., 105, 043304 (2009).

24. N. Jiang, A. Ji, and Z. Cao, J. Appl. Phys., 106, 013308 (2009).

25. J. Laimer, H. Reicher, and H. Störi, Vacuum, 84, 104 -107 (2010).

26. C. X. Wang and Y. P. Qiu, Surface Coatings Technol., 201, 6273-6277 (2007).

27. S. Y. Cheng, C. W. M. Yuen, C. W. Kan, K. K. L. Cheuk, W. A. Daoud, P. L. Lam, and W.Y. I. Tsoi, Vacuum, 84, 1466-1470 (2010).

28. L. Tian, H. Nie, N. P. Chatterton, C. J. BranfordWhite, Y. Qiu, and L. Zhu, Appl. Surface Sci., 257, 7113-7118 (2011).

29. J. Peran and S. E. Ražić, Texitle Res. J., 90, 11741197 (2019).

30. K. Gotoh, A. Yasukawa, and K. Taniguchi, J. Adhesion Sci. Technol., 25, 307-322 (2011).

31. K. Gotoh, A. Yasukawa and Y. Kobayashi, Polymer

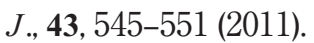

32. K. Gotoh, Y. Kobayashi, A. Yasukawa and Y. Ishigami, Colloid Polym. Sci., 290, 1005-1014 (2012).

33. K. Gotoh, A. Yasukawa, and Y. Kobayashi, Sen-i Gakkaishi, 68, 19-26 (2012).

34. K. Gotoh, A. Katsuura, A. Honma, and Y. Kobayashi, Sen-i Gakkaishi, 69, 169-176 (2013).

35. K. Gotoh, E. Shohbuke, Y. Kuroda, and Y. Kobayashi, Polymer J., 48, 889-896 (2016).

36. E. Shohbuke and K. Gotoh, J. Japan Research Association for Textile End-Uses, 59, 359-368 (2018).

37. K. Gotoh, E. Shohbuke, Y. Kobayashi, and H. Yamada, Colloids and Surfaces A: Physicochem. Eng. Aspects, 556, 1-10 (2018).

38. T. Matsuo, Textile Progress, 40, 87-121 (2008).

39. J. O. Iroh, "Polymer Data Handbook," (J. E. Mark Ed.), Oxford University Press, New York-Oxford, pp. 558-560 (1999).

40. L. M. Lander, L. S. Siewierski, W. J. Brittain, and E. A. Vogler, Langmuir, 9, 2237-2239 (1993).

41. D. P. Dowling, F. T. O’Neill, S. J. Langlais, and V. J. Law, Plasma process and Polymers, 8, 718-727
(2011).

42. S. Bhatt, J. Pulpytel, F. Krcma, V. Mazankova, and F. Arefi-Khonsari, J. Nano-and Electronic Physics, 8, 1021-1034 (2011).

43. K. Gotoh, M. Tagawa, N. Ohmae, and M. Tagawa, "Wettability of polyimide films modified by exposure to atomic oxygen”, Polymer Surface Modification: Relevance to Adhesion, Vol. 2 (K. L. Mittal, Ed), VSP, Utrecht, pp. 445-457 (2000).

44. K. Gotoh, E. Shohbuke, and G. Ryu, Textile Research J., 88, 1278-1289 (2018).

45. M. J. Owen and P. J. Smith, J. Adhesion Sci. Technol., 8, 1063-1075 (1994).

46. E. P. Everaert, H. C. van der Mei, J. de Vries, and H. J. Busscher, J. Adhesion Sci. Technol., 9, 1263 1278 (1995).

47. E. P. Everaert, H. C. van der Mei, and H. J. Busscher, J. Adhesion Sci. Technol., 10, 351-359 (1996).

48. B. K. Kim, K. S. Kim, K. Cho, and C. E. Park, J. Adhesion Sci. Technol., 15, 1805-1816 (2001).

49. M. Strobel and C. S. Lyons, J. Adhesion Sci. Technol., 17, 15-23 (2003).

50. Y. Ren, C. Wang and Y. Qiu, Surface Coating Technol., 207, 2670-2676 (2008).

51. J. Drelich, E. Chibowski, D. D. Meng, and K. Terpilowski, Soft Matter, 7, 9804-9828 (2011).

52. J. Drelich, J. S. Laskowski, M. Pawlik, and S. Veeramasuneni, J. Adhesion Sci. Technol, 11, 1399 1431 (1997).

53. Y. Uyama, H. Inoue, K. Ito, A. Kishida, and Y. Ikada, J. Colloid Interface Sci., 141, 275-279 (1991).

54. M. Tagawa, A. Yasukawa, K. Gotoh, M. Tagawa, N. Ohmae and M. Umeno, J Adhesion Sci Technol, 6, 763-776 (1992).

55. J. B. Cain, D. W. Francis, R. D. Venter, and A. W. Neumann, J. Colloid Interface Sci., 94, 123-130 (1983).

56. K. Gotoh, N. Kawamoto, E. Shohbuke, and Y. Kobayashi, J. Fiber Sci. Technol., 72, 80-88 (2016).

57. M. Tagawa, K. Gotoh, A. Yasukawa, and M. Ikuta, Colloid Polym. Sci., 268, 589-594 (1990).

58. C. X, Wang, Y. Ren, and Y. P. Qiu, Surface Coatings Technol., 202, 77-83 (2007).

59. C. X. Wang, Y. Liu, H. L. Xu, Y. Ren, and Y. P. Qiu, Appl. Surface Sci., 254, 2499-2505 (2008).

60. C. X. Wang, M. Du, and Y. P. Qiu, Adv. Mater. Res., 331, 356-359 (2011).

61. E. Chibowski, A. Ontiveros-Ortega, and R. PereaCarpio, J. Adhesion. Sci. Technol., 16, 1367-1404 
(2002).

62. K. Gotoh, M. Tagawa, N. Ohmae, H. Kinoshita, and M. Tagawa, Colloid Polym. Sci., 279, 214-220 (2001).

63. R. E. Johnson, Jr. and R. H. Dettre, J. Phys. Chem., 68, 1744-1750 (1964)

64. M. Tagawa, N. Ohmae, M. Umeno, K. Gotoh, A. Yasukawa, and M. Tagawa, Colloid Polym. Sci., 267, 702-706 (1989).

65. R. Mahlberg, HE-M Niemi, F. Denes, and R. M. Rowell, International Journal of Adhesion and Adhesives. 18, 283-297 (1998).

66. E. Finot, S. Roualdes, M. Kirchner, V. Rouessac, R. Berjoan, J. Durand, J-P. Goudonnet, and L. Cot, Appl Surface Sci. 187, 326-338 (2002).

67. K. H. Kale and S. S.Palaskar, J Applied Polymer Sci. 125, 3996-4006 (2012).

68. M. Šimor, A. Fiala, D. Kováčik, P. Hlídek, A. Wypkema, and R. Kuipers, Surface Coatings Technology, 201, 7802-7812 (2007).

69. S. Palaskar, K. H. Kale, G. S. Nadiger, and A. N. Desai, J Appl Poly Sci. 122, 1092-1100 (2011).

70. U. Lommatzsch, D. Pasedag, A. Baalmann, G. Ellinghorst, and H. -E. Wagner, Plasma Process Polym., 4, S1041-S1045 (2007).

71. M. Wolter, S. Bornholdt, M. Häckel, and H. Kersten, $J$ Achievements in Materials and Manufacturing Engineering, 37, 730-734 (2009).

72. V. Raballand, J. Benedikt, S. Hoffmann, M. Zimmermann and A. von Keudell, J Appl Phys, 105, 083304 (2009).

73. X. Zhu, F. Arefi-Khonsari, C. Petit-Etienne, and M. Tatoulian, Plasma Processes and Polymers, 2, 407 413 (2004).

74. F. Massines, N. Gherardi, A. Fornelli, and S. Martin, Surface and Coatings Technology, 200, 18551861(2005).
75. V. Raballand, J. Benedikt, S. Hoffmann, M. Zimmermann, and A. von Keudell, J. Appl. Phys. 105, 083304 (2009).

76. S. A. Starostin, P. Antony Premkumar, M. Creatore, H. de Vries, R. M. J. Paffen, and M. C. M. van de Sanden, Appl. Phys. Lett., 96, 061502 (2010).

77. K. Gotoh, J. Textile Engineering, 66, 97-101(2013).

78. Japanese Standards Association, "JIS handbook: Testing method of woven fabrics”, Japanese Standards Association, Tokyo, pp 1719-1812 (2007).

79. W. Cheng, P. F. Dunn, and R. M. Brach, J. Adhesion, 78, 929-965 (2002).

80. S. Eichenlaub, A. Gelb, and S. Beaudoin, J. Colloid Interface Sci, 280, 289-298 (2004).

81. O.-U. Nimittrakoolchai and S. Supothina, $J$. European Ceramic Society, 28, 947-952 (2008).

82. K. Gotoh, K. Harayama, and S. Tani, Tenside Surfactants Detergents, 52, 447-453(2015).

83. K. Gotoh and K. Harayama, Ultrasonics Sonochemistry, 20, 747-753 (2013).

84. Japanese Standards Association, "JIS handbook: Testing methods for water absorbency of textiles”, Japanese Standards Association, Tokyo, pp. 1024-1031 (2007).

85. E. W. Washburn, Phys. Rev., 17, 273-283 (1921).

86. K. Gotoh, T. Ohi, and R. Yasukawa, J. Fiber Sci. Technol., 73, 67-74 (2017).

87. R. Barni, C. Riccardi, E. Selli, M. R. Massafra, B. Marcandalli, F. Orsini, G. Poletti, and L. Meda, Plasma Process. Polym. 2, 64-72 (2005).

88. R. R. Deshmukh and N. V. Bhat, "Pretreatments of textiles prior to dyeing: Plasma processing”, in: Textile Dyeing (P. J. Hauser Ed.), pp. 33-56 (2011).

89. R. Yasukawa, Y. Sakai, H. Yamada, and K. Gotoh, J. Fiber Sci. Technol., 74, 122-132 (2018). 